\title{
Controlling the Optical and Catalytic Properties of Artificial Metalloenzyme Photocatalysts Using Chemogenetic Engineering
}

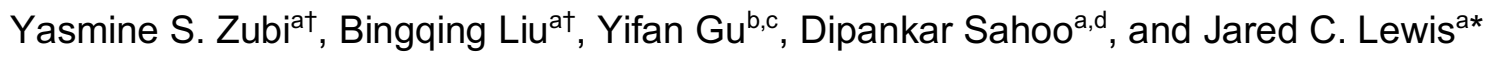

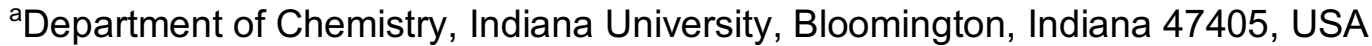 \\ bDepartment of Chemistry, University of Chicago, Chicago, IL, 60637, USA \\ ${ }^{\mathrm{c} C}$ urrent Address: 5F Lab Building, No. 100 Chongwen Road, Suzhou Industrial Park, Suzhou, \\ Jiangsu Province, P. R. China \\ ${ }^{d}$ Current Address: Department of Chemistry, Virginia Tech, Blacksburg, VA 24061, USA
}

†These authors contributed equally to this study.

\begin{abstract}
Visible light photocatalysis enables a broad range of organic transformations that proceed via single electron or energy transfer. Metal polypyridyl complexes are among the most commonly employed visible light photocatalysts. The photophysical properties of these complexes have been extensively studied and can be tuned by modifying the substituents on the pyridine ligands. On the other hand, ligand modifications that enable substrate binding to control reaction selectivity remain rare. Given the exquisite control that enzymes exert over electron and energy transfer processes in nature, we envisioned that artificial metalloenzymes (ArMs) created by incorporating $\mathrm{Ru}(\mathrm{II})$ polypyridyl complexes into a suitable protein scaffold could provide a means to control photocatalyst properties. This study describes approaches to create covalent and non-covalent ArMs from a variety of Ru(II) polypyridyl cofactors and a prolyl oligopeptidase scaffold. A panel of ArMs with enhanced photophysical properties were engineered, and the nature of the scaffold/cofactor interactions in these systems was investigated. These ArMs provided higher yields and rates than $\mathrm{Ru}(\mathrm{Bpy})_{3}{ }^{2+}$ for the reductive cyclization of dienones and the [2+2] photocycloaddition between $C$-cinnamoyl imidazole and 4-methoxystyrene, suggesting that protein scaffolds could provide a means to improve the efficiency of visible light photocatalysts.
\end{abstract}

\section{Keywords}

Visible-light photocatalysis, biocatalysis, artificial metalloenzyme, metal polypyridine complex

\section{Introduction}

Visible light photocatalysts enable a wide range of chemical reactions and provide access to compounds that are difficult to produce using other synthetic methods. ${ }^{1,2}$ After photoexcitation, these catalysts can react with substrates via single-electron transfer (SET) or energy transfer (ET) to produce high energy intermediates. In the former case, photoredox catalysis is enabled by a second SET event with a sacrificial oxidant or reductant (the order of reaction with the substrate and oxidant/reductant can also be reversed), while in the latter case, the bidirectional nature of ET leads to catalyst turnover. Both organic ${ }^{3,4}$ and inorganic ${ }^{5}$ molecules are used as photocatalysts, but metal polypyridyl complexes like $\operatorname{Ru}(\mathrm{Bpy})_{3}{ }^{2+}, \operatorname{Ir}(\mathrm{Ppy})_{3}$, and derivatives thereof are particularly valuable for synthetic organic methodology ${ }^{6}$. Upon absorbing visible light, these complexes efficiently form excited states that are suitably long-lived to enable reaction with organic substrates. ${ }^{7,8}$ Furthermore, metal polypyridyl complexes exhibit reversible redox properties and are not prone to decomposition or photobleaching. ${ }^{5}$

Structure-activity relationships have provided insight into the effects of polypyridine substituents on the photophysical and electronic properties of metal polypyridine complexes. ${ }^{5,9}$ Ligand modification has also been used to tune the selectivity of these complexes in reactions involving organic substrates. ${ }^{10}$ Given that many photocatalysts are only involved in the initial electron or 
energy transfer to/from a substrate and that the resulting high energy intermediates can undergo rapid subsequent reactions, the substrate must either be in a chiral environment during the excitation step and remain there during the selectivity-determining step or later engage with a chiral co-catalyst during the selectivity-determining step. ${ }^{11}$ Reactions proceeding via electron transfer can also proceed via radical chain mechanisms that do not involve the catalyst and compete with the desired closed catalytic cycle to erode catalyst controlled selectivity. ${ }^{12,13}$

Many enzyme-catalyzed reactions, ${ }^{14,15}$ including recently reported examples of non-native photocatalytic reactions, ${ }^{16}$ are initiated via SET, and highly efficient ET occurs in photosystems I and $\mathrm{II}^{17}$. The remarkable selectivity and specificity of these systems results from their ability to bind intermediates and cofactors throughout their respective catalytic cycles. On the other hand, the functional properties of such systems are limited relative to the rapidly expanding repertoire of synthetic photoredox ${ }^{18,19}$ and energy transfer ${ }^{3}$ catalysts. A variety of approaches have therefore been taken to explore the photophysical and photocatalytic capabilities of metal polypyridine complexes in the context of protein scaffolds. ${ }^{20}$ For example, Gray has extensively studied SET in $\mathrm{Ru}(\mathrm{II})$-polypyridyl modified-P450 BM3 enzymes ${ }^{21}$ and other scaffolds ${ }^{22-24}$. Cheruzel later developed related systems to enable light-driven P450 hydroxylation catalysis ${ }^{25}$ and to modulate the photophysical and catalytic properties of these systems through pyridyl ligand substitution ${ }^{26}$. Ward linked $\mathrm{Ru}(\mathrm{II})$-polypyridyl complexes to (strept)avidin via non-covalent biotin binding ${ }^{27}$ or covalent cysteine bioconjugation ${ }^{28,29}$ and explored SET in donor-photosensitizer-acceptor triads involving these systems. Importantly, in these cases, the metal polypyridine complexes were solvent exposed, often residing in shallow clefts with limited capacity to interact with the cofactor. While changes in the photophysical or redox properties of the protein-linked complexes were reported in these examples ${ }^{20-29}$ and others ${ }^{30-33}$, none of these systems were used as photocatalysts for direct transformations of organic substrates.

We envisioned that site-specific incorporation of metal polypyridine complexes into a suitable protein scaffold might enable greater control over the photophysical and catalytic properties of these complexes. Herein, we report the synthesis and characterization of a series of artificial metalloenzymes (ArMs) comprising different $\mathrm{Ru}(\mathrm{Bpy}){ }_{3}{ }^{2+}$ cofactors linked either covalently (1a-f) or non-covalently $(\mathbf{3 a}-\mathbf{i})$ to a prolyl oligopeptidase (POP) $)^{34}$ from Pyrococcus furiosus (Pfu) $)^{35}$ (Figure 1a). Systematic manipulation of both the cofactor and the POP scaffold were conducted to establish how structural changes impacted cofactor binding and photophysical properties. Improved binding, luminescence intensities, and luminescence lifetimes were observed for ArM variants due to hydrophobic and electrostatic interactions with residues in the POP active site. The catalytic activity of a panel of covalent ArMs was then evaluated using a reductive cyclization reaction proceeding via SET and a [2+2] cycloaddition enabled by ET. Yields of the desired products and reaction rates were increased by the engineered ArMs in both cases. These results indicate that POP variants can both modulate metal polypyridyl photophysical properties and improve photocatalysis yields, highlighting their potential as scaffolds for the further development of ArM photocatalysts.

\section{Results}

Scaffold Selection

To modulate ArM cofactor properties and catalysis, a protein scaffold must possess sufficient space to accommodate the cofactor(s) of interest while still allowing for beneficial interactions with the cofactor and potential substrates. ${ }^{36}$ The large size and octahedral geometry of metal polypyridyl complexes places significant constraints on the types of scaffolds that can be used. Our group has used Pfu POP as a scaffold for ArM formation via bioconjugation with bulky acridinium cofactors ${ }^{37}$ and dirhodium tetracarboxylate (2, Figure $\left.1 \mathrm{~b}\right)$ cofactors $^{38,39}$. MD simulations of the latter indicate that POP can fully encapsulate $\mathbf{2}$ while arraying active site residues proximal 
to it, and the high selectivity observed for a variety of reactions catalyzed by dirhodium ArMs indicates that these interactions significantly influence cofactor reactivity ${ }^{38,40}$. The POP scaffold was therefore selected for construction of ArM photocatalysts.

a Ru(II) Polypyridyl Complexes

Artificial Metalloenzyme (ArM)

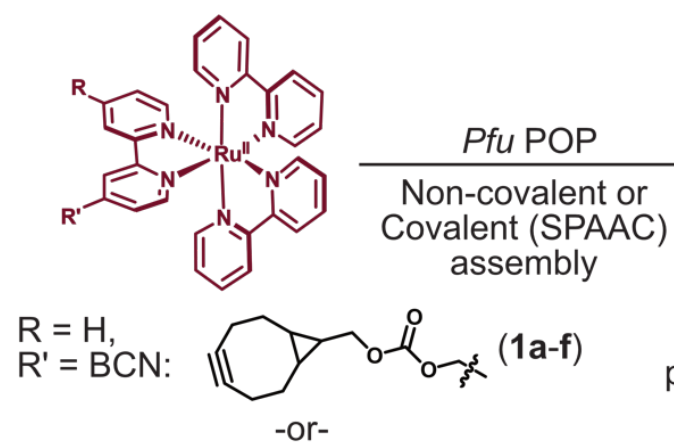

$\mathrm{R} / \mathrm{R}^{\prime}=\mathrm{H},{ }^{\mathrm{t}} \mathrm{Bu}, \mathrm{NH}_{2}, \mathrm{CO}_{2}{ }^{-}$, etc. $(3 \mathrm{a}-\mathrm{i})$

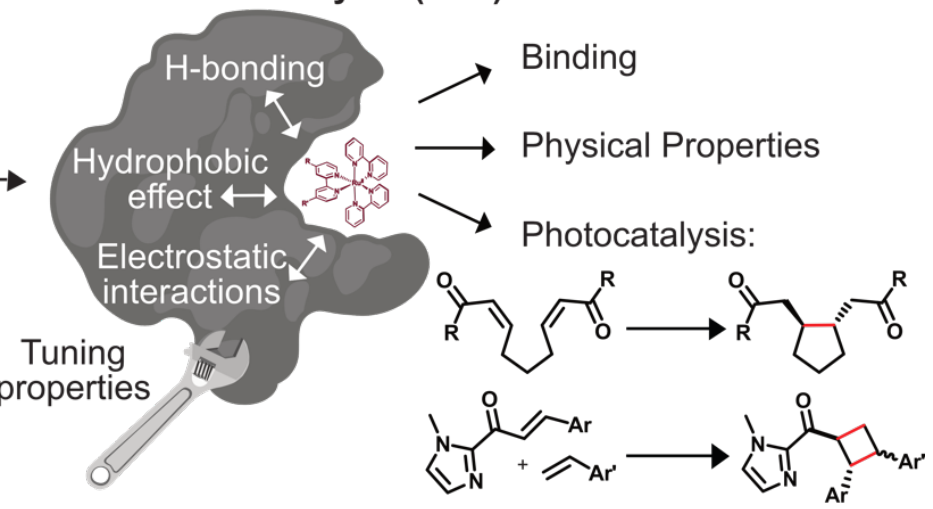

b Previous bulky cofactors for ArM and photocatalytic artificial enzyme formation:
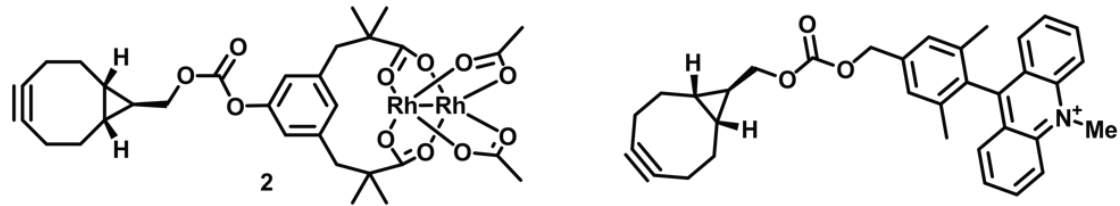

Figure 1. Overview of ArM Photocatalyst Preparation and Characterization. A) Combining conventional photocatalysts with a protein scaffold enables modulation of the cofactors' properties through interactions with the biomolecule. B) Previously reported dirhodium ${ }^{38,39}$ and acridinium $^{37}$ cofactors.

\section{Covalent ArM Preparation and Characterization}

In analogy to the dirhodium and acridinium systems noted above (Figure 1b), strain-promoted azide-alkyne cycloaddition (SPAAC) was used to covalently link endo-[6.1.0]-bicyclononyne $(\mathrm{BCN})$-substituted Ru(bpy) ${ }_{3}{ }^{2+}$ cofactor $1 \mathrm{a}$ within POP scaffolds containing a genetically encoded azidophenylalanine $(Z)$ residue ${ }^{41}$. Cofactor 1 a was synthesized by introducing 4-hydroxymethylBpy $\mathrm{ii}^{42}$ (prepared from commercially available methyl isonicotinate i) onto $\mathrm{Ru}(\mathrm{Bpy})_{2} \mathrm{Cl}_{2}{ }^{43}$ via ligand exchange to generate $\mathrm{iii}$ and then reacting this complex with carbonate iv ${ }^{44}$ (Scheme 1). The exo isomer of the cofactor (1b) was also prepared since these isomers could differentially orient the $\mathrm{Ru}(\mathrm{Bpy})_{3}{ }^{2+}$ fragment of $1 \mathrm{a}$ within the POP active site. Furthermore, because octahedral $\mathrm{Ru}(\mathrm{Bpy})_{3}{ }^{2+}$ complexes can adopt $\Delta$ and $\Lambda$ configurations, ${ }^{45}$ resolved $\Delta$ - and $\Lambda$-Ru(Bpy $)_{2}(\mathrm{Py})_{2}$ tartrate salts were used to prepare the endo/ $\Lambda$, endo/ $\Delta$, exo $/ \Lambda$, and exo/ $\Delta$ cofactors (1c-1f, respectively, Supplementary Figure 1).

POP-Z variants were then generated by genetically encoding the $Z$ residue at active site positions $53,99,326,338$, and 477 to explore the effects of cofactor linkage site on ArM function. All variants expressed in good yields ( $25-100 \mathrm{mg} / \mathrm{L})$, and intact ESI-MS confirmed the expected masses of the proteins (Supplementary Figure 2). SPAAC conditions developed for dirhodium ArMs were used to link $1 \mathrm{a}$ to these scaffolds, ${ }^{40}$ and intact ESI-MS again confirmed the expected masses of the ArMs (Figure 2A and Supplementary Figure 2). Notably, while bioconjugation of 2 is typically complete within 10 min, 6-18 hours of incubation was required to achieve $>99 \%$ bioconjugation of $1 \mathrm{a}$ to all POP-Z variants examined except for $\mathrm{POP}_{\mathrm{WT}}-\mathrm{Z}_{53}$, which was also complete within 10 min (Supplementary Figure 3). 


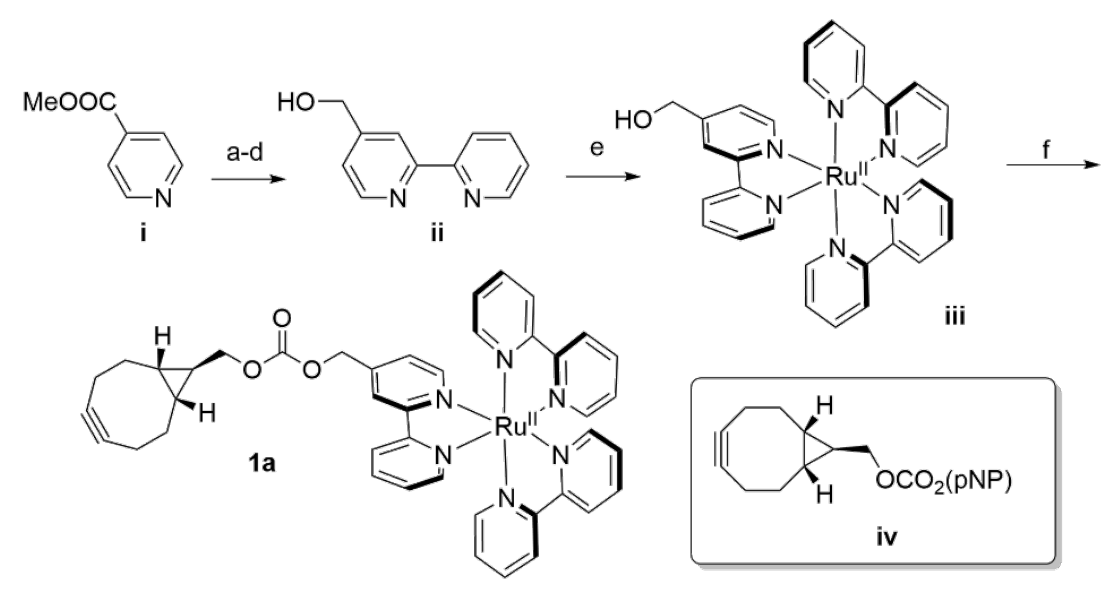

Scheme 1. Synthesis of $\mathrm{BCN}$-substituted $\mathrm{Ru}(\mathrm{Bpy})_{3}{ }^{2+}$ cofactor $\mathbf{1 a}(p N P=p$-nitrophenyl ester). (a) i, $\mathrm{H}_{2} \mathrm{O}_{2}$, acetic acid, $70{ }^{\circ} \mathrm{C}, \mathrm{O} / \mathrm{N}(92 \%)$; (b) pyridine $\mathrm{N}$-oxide, $\mathrm{Pd}(\mathrm{OAc})_{2}, \mathrm{~K}_{3} \mathrm{CO}_{3}$, 2-bromopyridine, $\left[\mathrm{P}(\mathrm{tBu})_{3} \mathrm{H}_{\mathrm{B}} \mathrm{BF}_{4}\right.$, toluene, $\mathrm{RT} \rightarrow 120{ }^{\circ} \mathrm{C}, \mathrm{O} / \mathrm{N}$ (54\%); (c) 4-methoxycarbonyl-2-(pyridin-2-yl)pyridine $\mathrm{N}$-oxide, $\mathrm{Pd} / \mathrm{C}, \mathrm{EtOH}, \mathrm{H}_{2}, \mathrm{RT}, 4$ hours (95\%); (d) 4-methoxycarbonyl-2-(pyridin-2-yl)pyridine, $\mathrm{LiBH}_{4}, \mathrm{THF}, 0{ }^{\circ} \mathrm{C}(1$ hour) $\rightarrow \mathrm{RT}, 12$ hours (83\%); (e) 2-(pyrid-2-yl)-4-hydroxymethyl-pyridine ii, cis- $\mathrm{Ru}(\mathrm{Bpy})_{2} \mathrm{Cl}_{2}$, EtOH, reflux (O/N) $\rightarrow \mathrm{RT}, \mathrm{NH}_{4} \mathrm{PF}_{6}, \mathrm{H}_{2} \mathrm{O}(54 \%)$; (f) iii, NaH, ACN, RT, 5 min $\rightarrow$ iv, THF, RT, 1 hour $\rightarrow$ acetone, $\mathrm{NH}_{4} \mathrm{PF}_{6}, \mathrm{H}_{2} \mathrm{O}(84 \%)$.

A variety of spectroscopic methods were next used to provide insight into binding of 1a-f within the different POP-Z variants. The $\lambda_{\max }$ values in the absorbance and emission spectra of the cofactors did not change significantly upon bioconjugation (Supplementary Figure 4-5), consistent with the fact that the orbital energies of $\mathrm{Ru}(\mathrm{Bpy}) 3_{3}{ }^{2+}$ and related complexes are generally not sensitive to changes in solvent/environment ${ }^{46}$. The luminescence lifetimes of the ArMs were also evaluated since it is known that the lifetime of luminophores like $\mathrm{Ru}(\mathrm{Bpy})_{3}{ }^{2+}$ increases in more hydrophobic environments, ${ }^{30,47,48}$ such as that expected within the POP active site, and substantial increases compared to the free complexes were observed (Table 1).

Table 1. Luminescence Lifetimes of Covalent ArMs

\begin{tabular}{|c|c|c|c|c|}
\hline Entry & Scaffold & Cofactor & Stereochemistry & Lifetime (ns) \\
\hline 1 & N/A & $3 a$ & racemic / n/a & 573 \\
\hline 2 & $\mathrm{~N} / \mathrm{A}$ & $\mathrm{a} 1 \mathrm{a}$ & racemic / endo & 530 \\
\hline 3 & $\mathrm{POP}_{\mathrm{WT}}-\mathrm{Z}_{53}$ & $1 a$ & racemic / endo & 765 \\
\hline 4 & $\mathrm{POP}_{\mathrm{WT}}-\mathrm{Z}_{99}$ & $1 a$ & racemic / endo & 791 \\
\hline 5 & $\mathrm{POP}_{\mathrm{WT}}-\mathrm{Z}_{326}$ & $1 \mathrm{a}$ & racemic / endo & 761 \\
\hline 6 & $\mathrm{POP}_{\mathrm{WT}}-\mathrm{Z}_{338}$ & $1 a$ & racemic / endo & 773 \\
\hline 7 & $\mathrm{POP}_{\mathrm{WT}}-\mathrm{Z}_{477}$ & $1 a$ & racemic / endo & 837 \\
\hline 8 & $\mathrm{POP}_{\mathrm{WT}}-\mathrm{Z}_{53}$ & $1 b$ & racemic / exo & 725 \\
\hline 9 & $\mathrm{POP}_{\mathrm{WT}}-\mathrm{Z}_{53}$ & $1 c$ & $\Lambda /$ endo & 737 \\
\hline 10 & $\mathrm{POP}_{\mathrm{WT}}-\mathrm{Z}_{53}$ & $1 d$ & $\Delta /$ endo & 715 \\
\hline 11 & $\mathrm{POP}_{\mathrm{WT}}-\mathrm{Z}_{53}$ & $1 e$ & $\Lambda /$ exo & 726 \\
\hline 12 & $\mathrm{POP}_{\mathrm{WT}}-\mathrm{Z}_{53}$ & $1 f$ & $\Delta /$ exo & 715 \\
\hline
\end{tabular}

aeasurements performed in $0.5 \%$ ACN. All other measurements were performed in $\mathrm{MQ} \mathrm{H}_{2} \mathrm{O}$.

Finally, CD spectroscopy was used to more directly interrogate possible interactions between 1af and the different protein scaffolds (Figure 2C and Supplementary Figure 6). Optically-active chiral molecules like $\mathrm{Ru}(\mathrm{Bpy})_{3}{ }^{2+}$ differentially absorb left- and right-circularly polarized light, ${ }^{49}$ and 
the resulting Cotton effects (i.e. CD signals near absorbance bands) can be used to analyze optical activity of metal complexes bound to a protein host ${ }^{50}$. While the apo proteins were spectroscopically silent above $250 \mathrm{~nm}$, positive and negative Cotton effects near $300 \mathrm{~nm}$ were observed for ArMs prepared with enantiopure cofactors (Figure 2C). Similar Cotton effects were observed for $\mathrm{POP}_{\mathrm{wT}}-\mathrm{Z}_{53}-1 \mathrm{a}$ (endo/racemic) and POP-Z $\mathrm{Z}_{53}-1 \mathrm{~b}$ (exo/racemic). These observations indicate that $\mathrm{POP}_{\mathrm{WT}}-\mathrm{Z}_{53}$ possesses sufficient affinity for the $\mathrm{Ru}(\mathrm{Bpy})_{3}{ }^{2+}$ fragment of $1 \mathrm{c} / 1 \mathrm{e}(\Lambda$ isomers) to enable partial resolution of racemic 1a during bioconjugation with an excess of this cofactor (2.75 equivalents). This apparent affinity explains the increased rate of bioconjugation for $\mathrm{POP}_{\mathrm{WT}} \mathrm{Z}_{53}$. Consistent with these observations, docking simulations of $1 \mathrm{e}$ revealed that the $\mathrm{Ru}(\mathrm{Bpy})_{3}{ }^{2+}$ fragment of $1 \mathrm{e}$ preferred to bind in a pocket that projected the BCN fragment toward residue 53 but not any of the other residues in the POP-Z variants examined (Figure 2D).

a

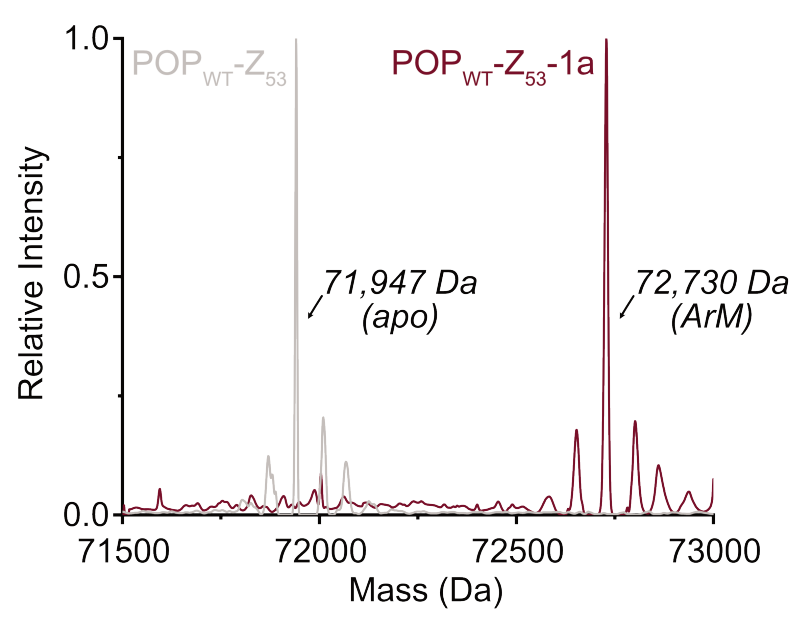

c
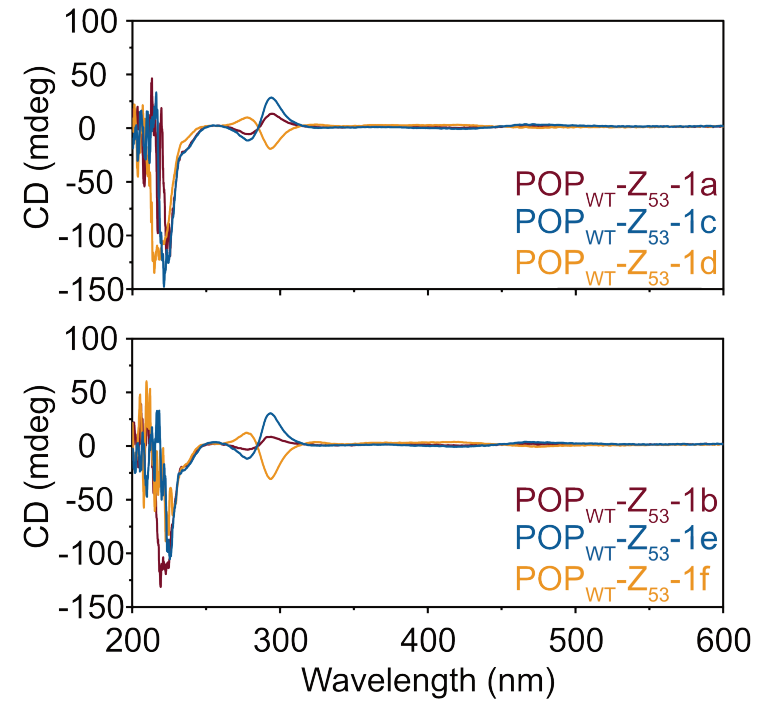

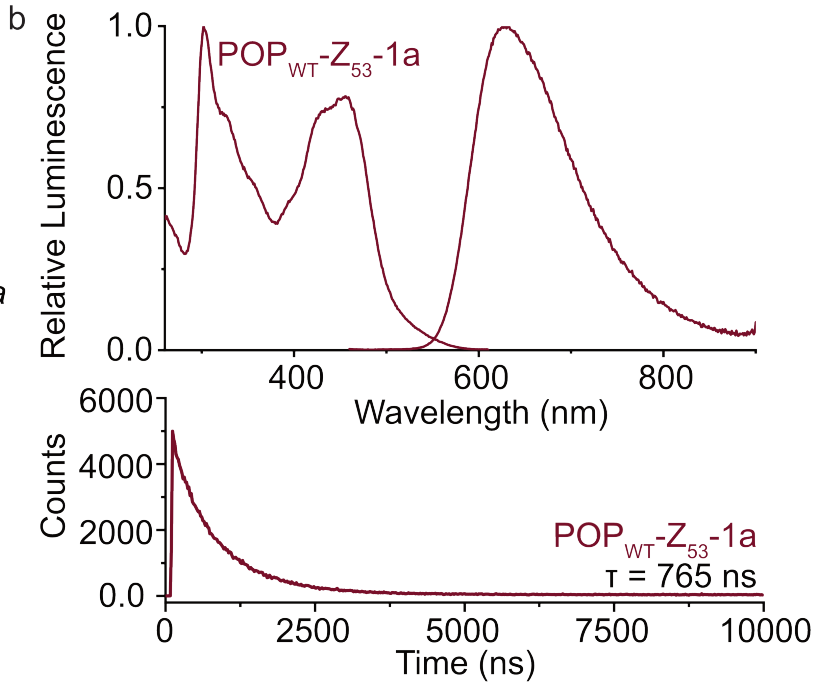

d

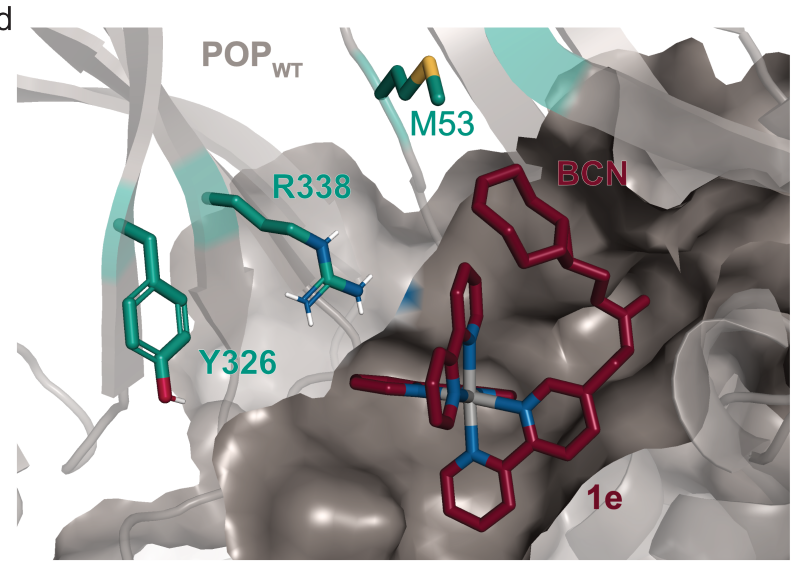

Figure 2. Covalent ArM Characterization. a) Intact ESI-MS characterization of $\mathrm{POP}_{\mathrm{WT}}-\mathrm{Z}_{53}$ before (theoretical: 71,947 Da) and after SPAAC reaction (theoretical: 72,723 Da) with cofactor 1a (endo/racemic). b) Excitation $\left(\lambda_{\text {exc }}=260-610 \mathrm{~nm}, \lambda_{\mathrm{em}}=620 \mathrm{~nm}\right)$ and emission $\left(\lambda_{\mathrm{exc}}=450 \mathrm{~nm}\right.$, $\left.\lambda_{\mathrm{em}}=460-900 \mathrm{~nm}\right)$ spectra (upper) for $\mathrm{POP}_{\mathrm{wT}}-\mathrm{Z}_{53}-1 \mathrm{a}$ ArM $(50 \mu \mathrm{M})$. Luminescence lifetime $\left(\lambda_{\mathrm{exc}}=\right.$ $450 \mathrm{~nm}, \lambda_{\mathrm{em}}=620 \mathrm{~nm}$ ) decay (lower) obtained for POP ${ }_{\mathrm{wT}}-Z_{53}-1 \mathrm{a}$ ArM $(50 \mu \mathrm{M})$. c) Circular dichroism spectra of various POP ${ }_{W T}-Z_{53}$ ArMs $(20 \mu \mathrm{M})$. d) Docking of cofactor $1 e$ (exo/ $\wedge$; crimson) with POP ${ }_{W T}$ (grey) scaffold using AutoDock Vina ${ }^{51}$. The alkyne functional group on the BCN 
moiety is oriented towards residue M53, and not towards other residues (e.g. Y326 and R338) targeted for incorporation of azidophenylalanine.

\section{Non-Covalent ArM Preparation and Characterization}

To further explore the apparent binding of the $\mathrm{Ru}(\mathrm{Bpy})_{3}{ }^{2+}$ fragments of 1a-f within $\mathrm{POP}$, the affinity of $\mathrm{POP}_{W T}$ toward a variety of substituted $\mathrm{Ru}(\mathrm{Bpy})_{3}{ }^{2+}$ complexes was examined. Luminescence lifetime titrations ${ }^{52-54}$ established that $\mathrm{Ru}(\mathrm{Bpy})_{3}{ }^{2+}(3 \mathrm{a})$ binds to $\mathrm{POP}_{\mathrm{wT}}$ with a $\mathrm{K}_{d}$ of $28 \pm 9 \mu \mathrm{M}$. Control experiments with BSA indicate that 3a possesses minimal non-specific binding affinity towards a similarly-sized globular protein (Supplementary Figure 7). The unexpected observation of $\mathbf{3 a}$ binding to POP thus provides a means to readily characterize the effects of changes in both protein and cofactor structure on binding affinity and photophysical properties.

We first aimed to increase the affinity of POP for $3 a$ via targeted mutations within the POP active site (Figure 3a). Several active site arginine and lysine residues (R55, R198, K255, and R338) that could have repulsive interactions with positively charged $\mathrm{Ru}(\mathrm{Bpy})_{3}{ }^{2+}$ derivatives were mutated to alanine in POP G99A. Active site tyrosine and tryptophan residues (W142 and Y326) were also mutated to alanine to avoid potential oxidation by $\mathrm{Ru}(\mathrm{Bpy}) 3_{3}{ }^{3+}$ derivatives, which could be accessed via oxidative quenching with an exogenous oxidant, ${ }^{55,56}$ giving $\mathrm{POP}_{\text {Neut. Residues }}$ 99, 142, and 326 , all projecting into the active site, were also mutated to aspartic acid in the POP Neut $_{\text {Scaffold }}$ to generate variant $\mathrm{POP}_{\mathrm{Neg}}$. With $\mathrm{K}_{d}$ values of $1.7 \pm 0.7 \mu \mathrm{M}$ and $1.1 \pm 1.7 \mu \mathrm{M}$ for $\mathrm{POP}_{\mathrm{Neut}}$ and

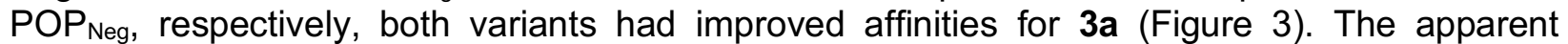
dissociation constant for $\mathrm{POP}_{\mathrm{Neg}}$ is only an upper limit due to experimental restrictions arising from the high affinity of the interaction (see Supplementary Information for details) ${ }^{57}$.

To confirm that $\mathbf{3 a}$ was binding in the active site of POP, a competition experiment was conducted using this complex and the known covalent POP inhibitor, Z-Pro-Prolinal (ZPP) ${ }^{58}$. Increasing inhibitor concentrations resulted in lower lifetime values, though the values were still significantly greater than the free cofactor, consistent with reduced affinity of the covalently modified active site for 3a (Supplementary Figure 8). In a series of complementary experiments inspired by the improved binding of $3 a$ to $\mathrm{POP}_{\mathrm{Neut}}$ and $\mathrm{POP}_{\mathrm{Neg}}$ relative to $\mathrm{POP}_{\mathrm{WT}}$, the ionic strength of the medium was increased to better solvate dicationic $3 a$ and thus disfavor binding in the POP active site (Figure $3 \mathrm{~b}$ and Supplementary Figures 9-10). Increased concentrations of $\mathrm{KCl}$ and various other salts/buffers significantly perturbed binding of $3 a$ to POP $_{\text {Neg. }}$. Furthermore, non-covalent ArMs treated with different aqueous salts during spin filtration retained no $3 \mathbf{a}$ while those treated only with water retained a significant amount of cofactor.

We next explored the extent to which the chirality of $\mathrm{Ru}(\mathrm{Bpy}) \mathrm{3}^{2+}$ derivatives and substitution on the Bpy ligands affects cofactor binding. As noted above, docking simulations suggest that BCNsubstituted cofactor 1c can bind to a pocket in the hinge region of the POP active site. Analogous simulations using $\mathrm{Ru}(\mathrm{Bpy}){ }_{3}{ }^{2+}$ complexes $3 \mathbf{b}$ and $3 \mathbf{c}$ ( $\Lambda$ and $\Delta$ configurations, respectively) indicate that this pocket could accommodate both cofactor enantiomers. These simulations also indicate that the 4,4' hydrogens of one Bpy ligand extended into this pocket with enough room to accommodate modifications at these positions (Figure 3c). Consistent with the docking simulations, comparable binding of enantiopure $\mathrm{Ru}(\mathrm{Bpy})_{3}{ }^{2+}$ complexes $3 \mathbf{b}$ and $3 \mathbf{c}$ to $\mathrm{POP}_{\mathrm{WT}}\left(\mathrm{K}_{\mathrm{d}}\right.$ values of $30 \mu \mathrm{M}$ and $37 \mu \mathrm{M}$, respectively) was observed (Table 2 and Supplementary Figure 11). Racemic complexes displaying 4,4'- $\mathrm{CO}_{2}^{-},-\mathrm{CH}_{2} \mathrm{CO}_{2}^{-},-\mathrm{CH}_{2} \mathrm{OH}$, -tBu, $-\mathrm{NH}_{2}$, and $-\mathrm{CH}_{2} \mathrm{NH}_{3}{ }^{+}$ substituents (3d-i) were prepared, and luminescence lifetime titrations (Figure $3 \mathrm{~d}$ and Supplementary Figure 12) revealed minor differences in affinity towards POP ${ }_{W T}$, except for $\mathbf{3 g}$ and $\mathbf{3 i}$, which bind $1.4-$ and 1.5 -fold tighter than $\mathbf{3 a}$, respectively (Table 2 ). 
We also observed different changes in the luminescence lifetime (Table 2) of the free vs. bound cofactors $\left(\Delta_{\text {lifetime}}\right)$, and in many cases, significant increases in the luminescence intensity of the cofactor (Supplementary Figure 13). Analogous binding experiments were also performed using POP $_{\text {Neg }}$ (Supplementary Figure 14-15). While similar trends were observed, there were notable differences between acid-substituted complex binding to the protein variants, as $\mathbf{3 d}$ had a

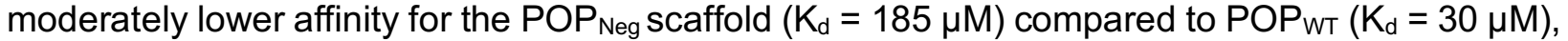
perhaps due to electrostatic repulsion between the anionic cofactor and the aspartate residues (i.e. 99D, 142D, and 326D) in the active site of POP ${ }_{\text {Neg. }}$

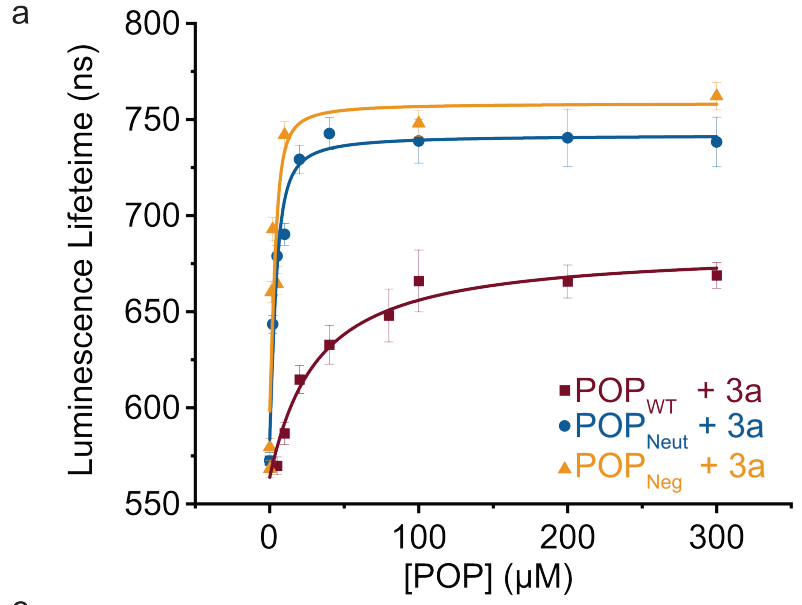

C

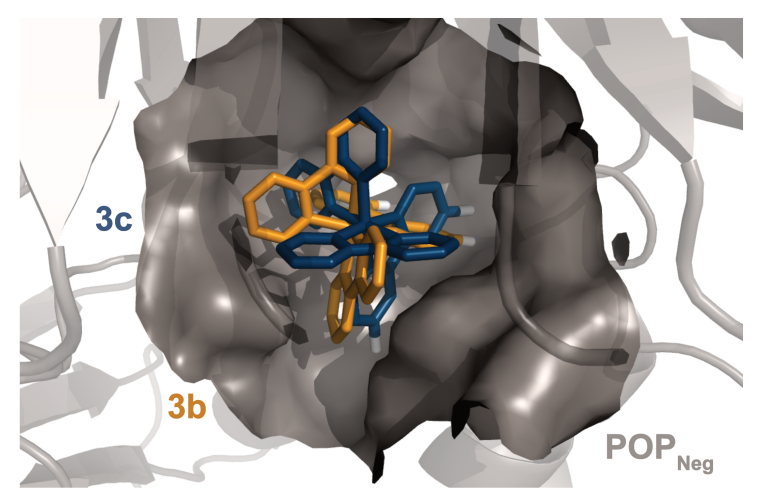

b
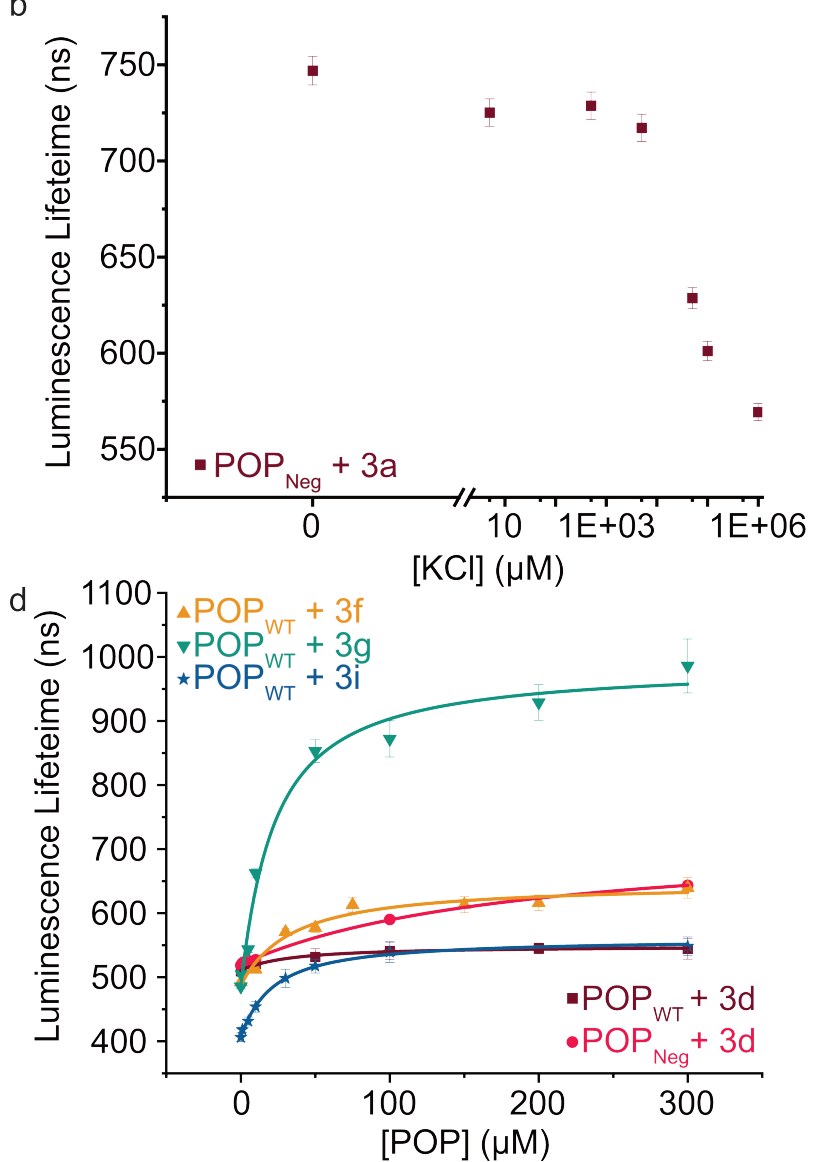

Figure 3. Modulating Non-Covalent ArM Formation through Protein and Cofactor Engineering. a) Luminescence lifetime titrations $\left(\lambda_{\mathrm{exc}}=450 \mathrm{~nm}, \lambda_{\mathrm{em}}=620 \mathrm{~nm}\right)$ demonstrate binding of $\mathrm{POP}$ variants to $\mathbf{3 a}$. b) $\mathbf{3 a}$ binding to $\mathrm{POP}_{\mathrm{Neg}}$ is disrupted by increasing concentrations of $\mathrm{KCl}$. c) Docking simulations between $\mathbf{3 b}$ (gold) and $\mathbf{3 c}$ (blue) with $\mathrm{POP}_{\mathrm{Neg}}$ (grey) reveal potential binding in the enzyme's active site. The 4,4'-hydrogens (white) of one ligand project into the hydrophobic pocket. d) Luminescence lifetime titrations ( $\lambda_{\text {exc }}=450 \mathrm{~nm}, \lambda_{\text {em }}=620-650 \mathrm{~nm}$ ) demonstrate binding of $\mathrm{POP}_{\mathrm{WT}}$ and $\mathrm{POP}_{\mathrm{Neg}}$ to various 4,4'-substituted ruthenium complexes. Plotted data points represent single measurements and error bars represent standard deviations resulting from single exponential tail fitting of decay data. Data were fit with a quadratic binding equation to give curves shown (Eq. 1 in the Supplementary Information). 
Table 2. Binding Affinities and Luminescence Lifetimes of Non-Covalent ArMs

\begin{tabular}{|c|c|c|c|c|c|}
\hline Entry & Variant & Cofactor & $\mathbf{R}$ & $K_{d}(\mu M)$ & $\Delta$ lifetime (ns) \\
\hline 1 & $\mathrm{POP}_{W T}$ & $3 a$ & $\overline{\mathrm{H}}$ & $28.3 \pm 8.8$ & 96 \\
\hline 2 & $\mathrm{POP}_{\text {Neut }}$ & $3 a$ & $\mathrm{H}$ & $1.65 \pm 0.71$ & 166 \\
\hline 3 & $\mathrm{POP}_{\mathrm{Neg}}$ & $3 a$ & $\mathrm{H}$ & $\mathrm{a} 1.08 \pm 1.70$ & 183 \\
\hline 4 & $\mathrm{POP}_{W T}$ & $3 b$ & $\mathrm{H}$ & $30.1 \pm 8.2$ & 110 \\
\hline 5 & $\mathrm{POP}_{W T}$ & $3 c$ & $\mathrm{H}$ & $36.8 \pm 11.1$ & 86 \\
\hline 6 & $\mathrm{POP}_{W T}$ & $3 d$ & $-\mathrm{CO}_{2}^{-}$ & $29.5 \pm 9.8$ & 35 \\
\hline 7 & $\mathrm{POP}_{\mathrm{Neg}}$ & $3 d$ & $-\mathrm{CO}_{2}^{-}$ & $185 \pm 20$ & 125 \\
\hline 8 & $\mathrm{POP}_{W T}$ & $3 e$ & $-\mathrm{CH}_{2} \mathrm{CO}_{2}^{-}$ & $30.8 \pm 10.1$ & 60 \\
\hline 9 & $\mathrm{POP}_{W T}$ & $3 f$ & $-\mathrm{CH}_{2} \mathrm{OH}$ & $30.8 \pm 10.4$ & 147 \\
\hline 10 & $\mathrm{POP}_{W T}$ & $3 g$ & $-t \mathrm{Bu}$ & $19.6 \pm 5.7$ & 500 \\
\hline 11 & $\mathrm{POP}_{W T}$ & $3 h$ & $-\mathrm{NH}_{2}$ & bNA & NA \\
\hline 12 & $\mathrm{POP}_{W T}$ & $3 \mathrm{i}$ & $-\mathrm{CH}_{2} \mathrm{NH}_{3}{ }^{+}$ & $18.7 \pm 2.0$ & 142 \\
\hline
\end{tabular}

${ }^{a}$ This value is only an estimated upper bound of affinity. The binding data exhibited characteristics consistent with being in the "titration" regime ${ }^{57}$. Refer to the Supplementary Information for more details. 'Low luminescence intensities precluded accurate determination of the lifetime of this complex at reasonable concentrations (i.e. $<<$ [POP]).

POP ArMs for Photocatalysis

Having established two approaches to link different photocatalysts to POP scaffolds, we next sought to evaluate the catalytic properties of these systems. Yoon has reported two mechanistically distinct reactions involving catalytic quantities of $\mathrm{Ru}(\mathrm{Bpy}){ }_{3}{ }^{2+}$ and a Brønsted acid co-catalyst. One of these involves 5-exo-trig reductive cyclization of dienones to generate 5membered rings via electron transfer (Scheme 2a) ${ }^{59}$ the second involves [2+2] cycloaddition between $C$-cinnamoyl imidazoles and different alkenes to give cyclobutanes via energy transfer (Scheme $2 b)^{60,61}$. Both reactions worked well in $10 \%$ aqueous ACN. Brønsted acid co-catalysts were not required in this medium, though a slightly acidic $\mathrm{pH}$ was optimal (Supplementary Fig. 16) for the cycloaddition (25 mM MES pH 6.0; pKa of related $\mathrm{N}$-methyl imidazole 7.0), and ascorbate served as a water-soluble reductant for the reductive cyclization reaction (Supplementary Table 1-2).

a<smiles>O=C(Br)/C=C\C=C/C(=O)Br</smiles>

$4(25 \mu \mathrm{M})$

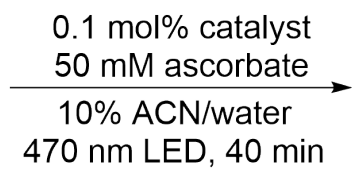

$470 \mathrm{~nm}$ LED, $40 \mathrm{~min}$

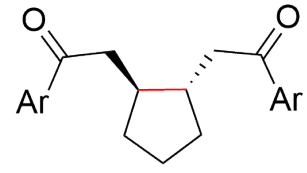

5

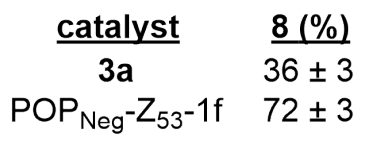

b

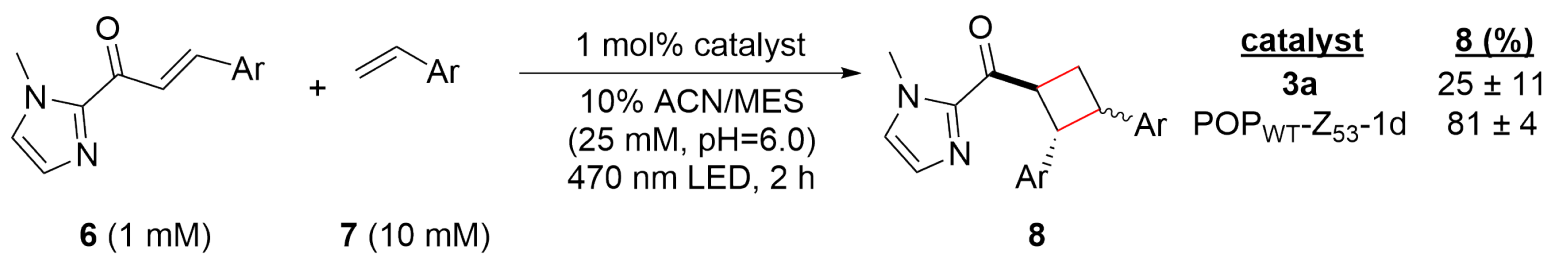

Scheme 2. a) Photoreductive cyclization reaction of dienone 4 and b) [2+2] photocycloaddition of cinnamoyl imidazole $\mathbf{6}$ and 4-methoxystyrene 7. Yields were determined by UHPLC relative to an internal standard, 1,3,5-trimethoxybenzene (TMB). Reactions were performed in triplicate $(n=3)$ and are reported as averages with standard deviations. 
The optimized conditions for both reactions were used to screen the reactivity and selectivity of a small panel of ArMs generated from different POP scaffolds. Only covalent ArMs were evaluated since ascorbate and MES, like other salts and buffers (vide supra), displaced the complex from non-covalent ArMs (Supplementary Figure 17). Reactions were conducted in an inert atmosphere wetbox containing a custom-built LED photoreactor compatible with 96-well plates to enable consistent irradiation samples (Supplementary Figure 18). The desired products, $\mathbf{5}$ and $\mathbf{8}$, were observed in all cases, and higher conversions were generally observed for ArM-catalyzed reactions relative to the free cofactor (Scheme 2, Supplementary Tables 3-4). Furthermore, increased rates of reaction were observed relative to $\mathrm{Ru}(\mathrm{Bpy})_{3}{ }^{2+}$ with a 2 -fold increase for reaction with $4\left(0.21 \mu \mathrm{M} / \mathrm{min}\right.$ vs. $0.41 \mu \mathrm{M} / \mathrm{min}$ for $3 a$ and $\mathrm{POP}_{\mathrm{Neg}}-Z_{53}-1 \mathrm{f}$, respectively; Supplementary Figure 19) and a 2.6-fold increase for reaction with $6(4.7 \mu \mathrm{M} / \mathrm{min}$ vs. $12.0 \mu \mathrm{M} / \mathrm{min}$ for $3 \mathrm{a}$ and $\mathrm{POP}_{\mathrm{wT}}-\mathrm{Z}_{53}-1 \mathrm{~d}$, respectively; Supplementary Figure 20).

\section{Discussion}

This study describes the formation of ArMs via covalent and non-covalent incorporation of $\mathrm{Ru}$ (II) polypyridine visible light photocatalysts into engineered POP variants. While our selection of metal polypyridine photocatalysts was motivated by their stability and the diversity of reactions that they catalyze ${ }^{5}$ their large size presents a challenge for ArM design. Privileged scaffolds like myoglobin ${ }^{62}$ or $\mathrm{LmrR}^{63}$ that bind a variety of planar complexes, for example, would likely not accommodate bulky cofactors like 1a-f. More open scaffolds like streptavidin do not fully encapsulate anchored catalysts, ${ }^{64}$ so their ability to modulate cofactor properties and control reactivity is limited (though fused lid structures such as that recently reported for streptavidin could correct this issue $)^{65}$. We previously established that Pfu POP is a versatile scaffold for ArM formation ${ }^{66}$ and that directed evolution can be used to engineer selective ArMs for a variety of dirhodium-catalyzed carbene addition and insertion reactions ${ }^{38,40}$. We have also used this scaffold to develop an artificial enzyme containing an acridinium cofactor (Figure 1b) for visible light photoredox catalysis. ${ }^{37}$ This system catalyzes sulfide oxidation via SET, but no selectivity was obtained, presumably due to poor substrate binding within the active site. Rapid photobleaching of the acridinium cofactor limits the potential of this system even if selectivity could be achieved.

Preliminary efforts to develop POP ArM photocatalysts focused on cofactor 1a (Figure 1a), which contains a [6.1.0]-bicyclononyne anchor for SPAAC to proteins containing a genetically encoded azidophenylalanine residue. SPAAC proceeded efficiently, giving $>99 \%$ bioconjugation in all cases. Interestingly, the linkage site strongly influenced the rate of SPAAC, and POP ${ }_{W T}-Z_{53}$ was even able to partially resolve racemic cofactor $1 \mathrm{a}$ to form an ArM enriched in the $\Lambda$ cofactor enantiomer. Similar stereoselective bioconjugation of ruthenium complexes to proteins has been described previously. ${ }^{30-33}$ For example, Salmain showed that Michael addition of the active site cysteine of papain to maleimide-substituted $\mathrm{Ru}(\mathrm{II})$ complexes proceeded stereoselectively and that substituents on these complexes affect bioconjugation rates. ${ }^{30}$ Tiede later showed that bioconjugation of PpcA via cysteine alkylation also led to cofactor resolution, and differences in stereoselectivity based on bioconjugation site were noted. ${ }^{31}$ Together, these studies provide precedent for the site-dependent bioconjugation rate acceleration observed in the current study, but both involved relatively small scaffolds that left their cofactors solvent exposed. POP is large enough to accommodate both the cofactor and potential substrate(s) in its hydrophobic active site, and secondary Ru(II) polypyridine binding provides a means to reduce cofactor movement, which has been found to improve the activity and selectivity of ArMs generated from other scaffolds ${ }^{67,68}$.

Although covalent cofactor bioconjugation allows for complete removal of free cofactor and associated background spectroscopic signals or catalysis, ${ }^{40}$ it necessitates the incorporation of bioorthogonal linkage sites into both cofactor and scaffold ${ }^{41}$. High affinity non-covalent cofactor 
binding eliminates these issues and inherently provides a direct interface between active site residues and the cofactor to modulate cofactor properties. ${ }^{69}$ Consistent with the apparent binding of the $\mathrm{Ru}(\mathrm{II})$ fragment of cofactor $1 \mathrm{a}$, POP exhibited $\mathrm{Ru}(\mathrm{Bpy}) \mathrm{s}_{3}{ }^{2+}$ binding affinities in the $\mu \mathrm{M}$ range. Reduced luminescence lifetimes for this system in the presence of a known covalent inhibitor of POP, Z-Pro-Prolinal, ${ }^{58}$ and negligible binding to BSA highlighted the unique affinity of the POP active site for $\mathrm{Ru}(\mathrm{Bpy})_{3}{ }^{2+}$. This fortuitous discovery provides a starting point to develop noncovalent ArM photocatalysts in which both cofactor and scaffold can be tuned to modulate cofactor binding, photophysical properties, and reactivity.

Initial non-covalent ArM engineering efforts focused on further improving cofactor binding. Given that $\mathrm{Ru}(\mathrm{Bpy}){ }_{3}{ }^{2+}$ is dicationic, several positively charged residues in the POP active site were mutated to Ala or Asp to create $\mathrm{POP}_{\text {Neut }}$ and $\mathrm{POP}_{\text {Neg, }}$, respectively, with the goal of improving electrostatic scaffold/cofactor complementarity. This approach mirrors analogous charge complementation in both natural proteins (e.g. cytochrome $\mathrm{f}$ in photosystem I) ${ }^{70-72}$ and synthetic systems (e.g. methyl viologen in streptavidin) ${ }^{29}$. Non-covalent binding in POP $_{\text {Neut }}$ and POP $_{\text {Neg }}$ increases substantially, and $\mathrm{K}_{d}$ values approaching the $\mathrm{nM}$ regime are observed for $\mathrm{Ru}(\mathrm{Bpy})_{3}{ }^{2+}$ binding. The electrostatic nature of cofactor binding in these systems is supported by control experiments in which added $\mathrm{KCl}$ and other salt solutions that could better solvate the cofactor significantly reduce binding of $3 a$ even to $\mathrm{POP}_{\mathrm{Neg}}$. Cofactor substitution was also found to modulate binding. Docking simulations were used to guide the installation of substituents on the 4 and 4' positions of one Bpy ligand that could interact with the protein via different mechanisms (e.g. hydrophobic effect, hydrogen bonding, ion pairing, etc.). tBu-substituted complex $\mathbf{3 g}$ was found to bind better than the homoleptic complex $3 a$, highlighting the importance of the hydrophobic effect for cofactor binding.

The $\mathrm{Ru}(\mathrm{II})$ polypyridine ArMs developed in this study also provide a unique platform to tune and study the photophysical properties and reactivity of visible light photocatalysts. Both covalent and non-covalent ArMs exhibit increased luminescence lifetimes and intensities relative to free cofactors. These changes were dependent on the identities of the cofactor and scaffold. For example, while the average increase in the luminescence lifetime upon non-covalent binding to $\mathrm{POP}_{\mathrm{WT}}$ was around $100 \mathrm{~ns}$ for most cofactors, the lifetime of $\mathbf{3 g}$ was increased by $500 \mathrm{~ns}$ (from $486 \mathrm{~ns}$ to $986 \mathrm{~ns})$, similar to the lifetime of $\mathrm{Ru}(\mathrm{Bpy})_{3}{ }^{2+}$ in deoxygenated acetonitrile $(930 \mathrm{~ns})^{5,8}$. Similar enhancements in different $\mathrm{Ru}(\mathrm{II})$ polypyridine-protein conjugates have been ascribed to $\mathrm{Ru}(\mathrm{II})$ polypyridine binding in hydrophobic sites that can shield the complexes from luminophorequenching oxygen. ${ }^{30}$ Both of these mechanisms could be operative for POP ArMs given the large, hydrophobic Ru(II) polypyridine binding pocket within the POP active site (Figure 3c). The site of cofactor attachment and electrostatic complementation were also observed to modulate the luminescence of covalent cofactors. For instance, ArMs constructed by bioconjugating 1a at different active site residues had lifetimes ranging from $761 \mathrm{~ns}$ to $837 \mathrm{~ns}$ (Table 1), and the addition of an anionic carboxylate group (3d) limited the increase in lifetime to only 35 ns upon non-covalent association with POP ${ }_{W T}$ vs. 125 ns for POP $_{\text {Neg, }}$, highlighting the dependence of cofactor properties on the local protein environment. The importance of linker design/placement in synthetic systems was recently demonstrated in a systematic study focused on the effects of ligand modification (i.e. length and chiral configuration) and chromophore placement on the photophysics of Sulforhodamine B. ${ }^{73}$ While we only investigated one linker in this study, the rigidity, length, and stereochemistry of the $\mathrm{BCN}$ moiety could be tuned to further control the nature of protein-cofactor interactions.

Finally, covalent ArM photocatalysts exhibited promising activity towards two mechanistically distinct transformations. In the first, 5-exo-trig reductive cyclization of a dienone (e.g. 4) generates a cyclopentane (e.g. 5) via SET using a sacrificial reductant. ${ }^{59}$ In the other model reaction, [2+2] 
cycloaddition between a C-cinnamoyl imidazole (e.g. 6) and an electron-rich styrene like 4methoxystyrene yields a cyclobutane (e.g. 8) ${ }^{60,61}$ In both cases, enhanced yields and rate acceleration compared to the free cofactor were observed under optimized aqueous conditions. These improvements could result from increased local concentration of both substrate and photocatalyst within the ArM active site relative to solution. The increased luminescence lifetime of ArM photocatalysts could also improve yields since longer-lived excited states increase the probability of the catalyst encountering substrates in a bimolecular reaction. Small differences in the diastereomeric ratios (d.r.) for $\mathrm{ArM}$ - and $\mathrm{Ru}(\mathrm{Bpy})_{3}{ }^{2+}$-catalyzed [2+2] cycloaddition were observed (1.2 and 1.5, respectively; Supplementary Figure 21), suggesting that the protein scaffold could modulate reaction stereoselectivity and providing a starting point for further engineering efforts.

\section{Conclusion}

In this study, we developed a series of covalent and non-covalent ArMs using metal polypyridyl cofactors and a prolyl oligopeptidase scaffold. Modifications to both the scaffold and the cofactor were used to increase cofactor binding affinity and extend its luminescence lifetime, an important metric when assessing the potential of a photocatalyst. The ArM photocatalysts exhibited good activity toward reactions that proceed via SET (reductive cyclization) and ET ([2+2] photocycloaddition) under optimized aqueous reaction conditions. Moreover, the yields of the desired products and rates of reactions were enhanced for ArM-catalyzed reactions compared to $\mathrm{Ru}(\mathrm{Bpy})_{3}{ }^{2+}$ under aqueous conditions. The ability of POP to bind and modulate the properties of different $\mathrm{Ru}(\mathrm{II})$ cofactors suggests that ArM photocatalysts could serve as a general platform for the further development of diverse catalysts with tunable photophysical properties and reactivity.

\section{Supplementary Information}

Electronic supplementary information (ESI) available: Supplemental figures, detailed procedures and results for all reported experiments, and data for compound characterization.

\section{References}

1 C. K. Prier, D. A. Rankic and D. W. C. MacMillan, Chem. Rev., 2013, 113, 5322-5363.

2 L. Marzo, S. K. Pagire, O. Reiser and B. König, Angew. Chem. Int. Ed., 2018, 57, 1003410072.

3 F. Strieth-Kalthoff, M. J. James, M. Teders, L. Pitzer and F. Glorius, Chem. Soc. Rev., 2018, 47, 7190-7202.

$4 \quad$ N. A. Romero and D. A. Nicewicz, Chem. Rev., 2016, 116, 10075-10166.

5 D. M. Arias-Rotondo and J. K. McCusker, Chem. Soc. Rev., 2016, 45, 5803-5820.

$6 \quad$ T. Koike and M. Akita, Inorg. Chem. Front., 2014, 1, 562-576.

$7 \quad$ K. Kalyanasundaram, Coord. Chem. Rev., 1982, 46, 159-244.

8 A. Juris, V. Balzani, F. Barigelletti, S. Campagna, P. Belser and A. von Zelewsky, Coord. Chem. Rev., 1988, 84, 85-277.

9 D. van der Westhuizen, K. G. von Eschwege and J. Conradie, Electrochim. Acta, 2019, 320, 134540.

10 J. Zheng, W. B. Swords, H. Jung, K. L. Skubi, J. B. Kidd, G. J. Meyer, M. H. Baik and T.

P. Yoon, J. Am. Chem. Soc., 2019, 141, 13625-13634.

11 M. J. Genzink, J. B. Kidd, W. B. Swords and T. P. Yoon, Chem. Rev., 2021, DOI: 10.1021/acs.chemrev.1c00467.

12 M. P. Sibi, S. Manyem and J. Zimmerman, Chem. Rev., 2003, 103, 3263-3295.

13 T. P. Yoon, Acc. Chem. Res., 2016, 49, 2307-2315.

14 P. A. Frey, Annu. Rev. Biochem., 2003, 70, 121-148.

15 H. R. Williamson, B. A. Dow and V. L. Davidson, Bioorg. Chem., 2014, 57, 213-221.

16 T. K. Hyster, Synlett, 2019, 31, 248-254. 
N. Nelson and W. Junge, Annu. Rev. Biochem., 2015, 84, 659-683.

R. C. McAtee, E. J. McClain and C. R. J. Stephenson, Trends Chem., 2019, 1, 111-125.

M. H. Shaw, J. Twilton and D. W. C. MacMillan, J. Org. Chem., 2016, 81, 6898-6926.

Q. Lam, M. Kato and L. Cheruzel, Biochim. Biophys. Acta, 2016, 1857, 589-597.

M. E. Ener, Y. T. Lee, J. R. Winkler, H. B. Gray and L. Cheruzel, Proc. Natl. Acad. Sci. U.

S. A., 2010, 107, 18783-18786.

J. R. Winkler and H. B. Gray, J. Am. Chem. Soc., 2014, 136, 2930-2939.

H. B. Gray and J. R. Winkler, Annu. Rev. Biochem., 2003, 65, 537-561.

J. R. Winkler and H. B. Gray, Chem. Rev., 2013, 114, 3369-3380.

N. H. Tran, N. Huynh, T. Bui, Y. Nguyen, P. Huynh, M. E. Cooper and L. E. Cheruzel, Chem. Commun. (Camb)., 2011, 47, 11936-11938.

26 H. Shalan, A. Colbert, T. T. Nguyen, M. Kato and L. Cheruzel, Inorg. Chem., 2017, 56, 6558-6564.

27 A. Loosli, U. E. Rusbandi, J. Gradinaru, K. Bernauer, C. W. Schlaepfer, M. Meyer, S. Mazurek, M. Novic and T. R. Ward, Inorg. Chem., 2005, 45, 660-668.

28 S. G. Keller, A. Pannwitz, F. Schwizer, J. Klehr, O. S. Wenger and T. R. Ward, Org. Biomol. Chem., 2016, 14, 7197-7201.

29 S. G. Keller, A. Pannwitz, H. Mallin, O. S. Wenger and T. R. Ward, Chem. - A Eur. J., 2017, 23, 18019-18024.

30 P. Haquette, J. Jacques, S. Dagorne, C. Fosse and M. Salmain, Eur. J. Inorg. Chem., 2010, 2010, 5087-5095.

31 N. S. Ponomarenko, O. Kokhan, P. R. Pokkuluri, K. L. Mulfort and D. M. Tiede, Photosynth. Res., 2020, 143, 99-113.

J. Luo, J. F. Wishart and S. S. Isied, J. Am. Chem. Soc., 1998, 120, 12970-12971.

I. J. Dmochowski, J. R. Winkler and H. B. Gray, J. Inorg. Biochem., 2000, 81, 221-228.

S. Z and P. L, Curr. Protein Pept. Sci., 2008, 9, 96-107.

K. Ellis-Guardiola, H. Rui, R. L. Beckner, P. Srivastava, N. Sukumar, B. Roux and J. C. Lewis, Biochemistry, 2019, 58, 1616-1626.

36 S. Abe, T. Ueno and Y. Watanabe, Top. Organomet. Chem., 2009, 25, 25-43.

37 Y. Gu, K. Ellis-Guardiola, P. Srivastava and J. C. Lewis, ChemBioChem, 2015, 16, 18801883.

38 D. M. Upp, R. Huang, Y. Li, M. J. Bultman, B. Roux and J. C. Lewis, Angew. Chemie Int. Ed., 2021, DOI:10.1002/anie.202107982. J. C. Lewis, Acc. Chem. Res., 2019, 52, 576-584.

H. Yang, A. M. Swartz, H. June Park, P. Srivastava, K. Ellis-Guardiola, D. M. Upp, G. Lee, K. Belsare, Y. Gu, C. Zhang, R. E. Moellering and J. C. Lewis, Nat. Chem., 2018, 10, 318-324.

H. Yang, P. Srivastava, C. Zhang and J. C. Lewis, ChemBioChem, 2014, 15, 223-227.

42 Y. Kobayashi, M. Hoshino, T. Kameda, K. Kobayashi, K. Akaji, S. Inuki, H. Ohno and S. Oishi, Inorg. Chem., 2018, 57, 5475-5485.

43 L. Wang, H. Yin, M. A. Jabed, M. Hetu, C. Wang, S. Monro, X. Zhu, S. Kilina, S. A. McFarland and W. Sun, Inorg. Chem., 2017, 56, 3245-3259.

44 J. Dommerholt, S. Schmidt, R. Temming, L. J. A. Hendriks, F. P. J. T. Rutjes, J. C. M. van Hest, D. J. Lefeber, P. Friedl and F. L. van Delft, Angew. Chemie Int. Ed., 2010, 49, 9422-9425.

45 X. Hua and A. von Zelewsky, Inorg. Chem., 1995, 34, 5791-5797.

46 N. R. M. Simpson, M. D. Ward, A. F. Morales and F. Barigelletti, J. Chem. Soc. Dalt. Trans., 2002, 2449-2454.

47 M. Y. Berezin and S. Achilefu, Chem. Rev., 2010, 110, 2641.

48 S. H. Mejías, G. Roelfes and W. R. Browne, Phys. Chem. Chem. Phys., 2020, 22, 12228-12238. 
R. D. Gillard, in Progress in Inorganic Chemistry, ed. F. A. Cotton, John Wiley \& Sons Inc., New York, $1^{\text {st }}$ edn, 1966, vol. 7, ch. 4, pp. 215-276.

50 L. Quintanar and L. Rivillas-Acevedo, Methods Mol. Biol., 2013, 1008, 267-297.

O. Trott and A. J. Olson, J. Comput. Chem., 2010, 31, 455-461.

H. Szmacinski, E. Terpetschnig and J. R. Lakowicz, Biophys. Chem., 1996, 62, 109-120.

53 S. P. Bernhard, C. K. Goodman, E. G. Norton, D. G. Alme, C. M. Lawrence and M. J. Cloninger, ACS Omega, 2020, 5, 29017-29024.

54 J. N. Lampe and W. M. Atkins, Biochemistry, 2006, 45, 12204-12215.

55 M. Sjödin, S. Styring, B. Åkermark, L. Sun and L. Hammarström, J. Am. Chem. Soc., 2000, 122, 3932-3936.

56 M. T. Zhang and L. Hammarström, J. Am. Chem. Soc., 2011, 133, 8806-8809.

57 I. Jarmoskaite, I. Alsadhan, P. P. Vaidyanathan and D. Herschlag, Elife, 2020, 9, 1-34.

58 M. N. Harris, J. D. Madura, L. J. Ming and V. J. Harwood, J. Biol. Chem., 2001, 276, 19310-19317.

59 J. Du, L. R. Espelt, I. A. Guzei and T. P. Yoon, Chem. Sci., 2011, 2, 2115-2119.

60 E. M. Sherbrook, H. Jung, D. Cho, M. H. Baik and T. P. Yoon, Chem. Sci., 2020, 11, 856-861.

61 E. M. Sherbrook, M. J. Genzink, B. Park, I. A. Guzei, M. H. Baik and T. P. Yoon, Nat. Commun., 2021, 12, 5735.

62 K. Oohora and T. Hayashi, Dalt. Trans., 2021, 50, 1940-1949.

63 G. Roelfes, Acc. Chem. Res., 2019, 52, 545-556.

64 T. Heinisch and T. R. Ward, Acc. Chem. Res., 2016, 49, 1711-1721.

65 F. Christoffel, N. V. Igareta, M. M. Pellizzoni, L. Tiessler-Sala, B. Lozhkin, D. C. Spiess, A. Lledós, J. D. Maréchal, R. L. Peterson and T. R. Ward, Nat. Catal., 2021, 4, 643-653

66 P. Srivastava, H. Yang, K. Ellis-Guardiola and J. C. Lewis, Nat. Commun., 2015, 6, 7789.

67 H. J. Davis and T. R. Ward, ACS Cent. Sci., 2019, 5, 1120-1136.

68 J. R. Carey, S. K. Ma, T. D. Pfister, D. K. Garner, H. K. Kim, J. A. Abramite, Z. Wang, Z. Guo and Y. Lu, J. Am. Chem. Soc., 2004, 126, 10812-10813.

69 L. Fruk, C. H. Kuo, E. Torres and C. M. Niemeyer, Angew. Chemie Int. Ed., 2009, 48, 1550-1574.

70 E. L. Gross, Photosynth. Res., 1993, 37, 103-116.

71 E. J. Haddadian and E. L. Gross, Biophys. J., 2005, 88, 2323-2339.

72 M. R. Redinbo, T. O. Yeates and S. Merchant, J. Bioenerg. Biomembr., 1994, 26, 49-66.

73 M. Delor, J. Dai, T. D. Roberts, J. R. Rogers, S. M. Hamed, J. B. Neaton, P. L. Geissler,

M. B. Francis and N. S. Ginsberg, J. Am. Chem. Soc., 2018, 140, 6278-6287.

\section{Author Contributions}

J.C.L.: conceptualization; writing - original draft; writing - review and editing; visualization; project administration; funding acquisition

Y.S.Z.: conceptualization; methodology; validation; formal analysis; investigation; resources; writing - original draft; writing - review \& editing; and visualization.

B.L.: methodology; validation; formal analysis; investigation; resources; visualization; and writing - review \& editing.

Y.G.: conceptualization; methodology; and resources.

D.S.: resources

\section{Acknowledgements}

This study was supported by the U.S. Army Research Laboratory and the U.S. Army Research Office under Contract/Grant W911NF-19-1-0074 and by an NSF CAREER Award to J.C.L. (CHE1351991). Y.S.Z gratefully acknowledges receipt of a predoctoral fellowship from the Graduate 
Training Program in Quantitative and Chemical Biology at Indiana University (T32 GM131994). NMR data were acquired on a spectrometer funded by the NSF (MRI CHE-1920026) using a Prodigy probe that was partially funded by the Indiana Clinical and Translational Sciences Institute. We thank Dr. Jonathan Trinidad for assistance with intact protein ESI-MS; Dr. Giovanni Gonzalez-Gutierrez for assistance with various instrumentation in the IU Physical Biochemistry Instrumentation Facility and for allowing us to borrow a low-volume cuvette for luminescence measurements; and Prof. Amar Flood for access to a UV-Vis spectrophotometer and a fluorometer. We thank IU Mechanical Instrument Services and IU Electronic Instrument Services, including Mr. John Poehlman and Ms. Rose Burchfield in particular, for assistance with the design and fabrication of the photoreactor used in these studies.

\section{TOC Graphic}

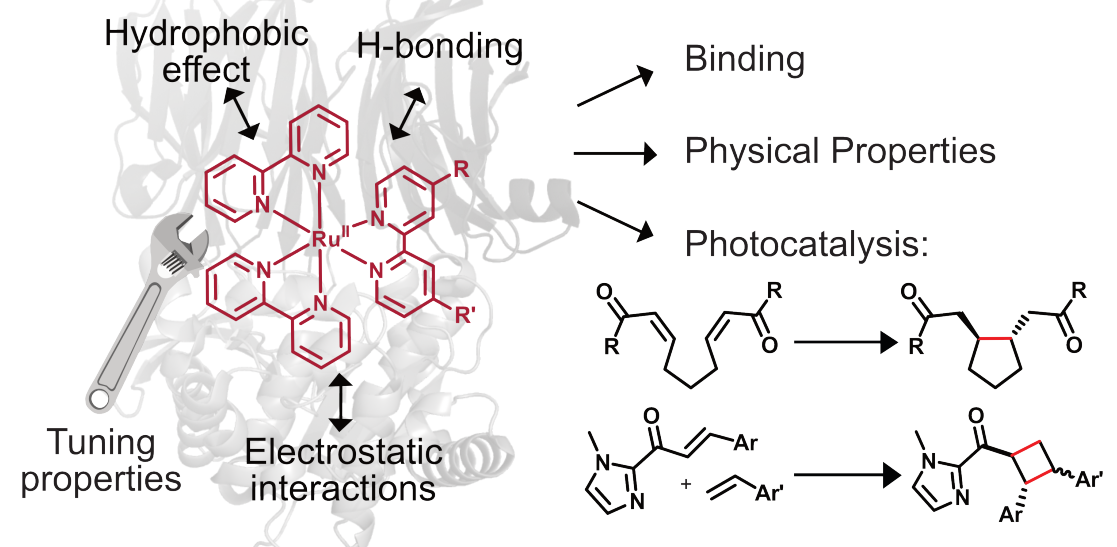

